\title{
The Study on NIMBY of Garbage Incineration under "Five Water Governance"-—Based on Zhejiang Province
}

\author{
Jinjiang $\mathrm{He}^{1, \mathrm{a}}$, Qi Zhang ${ }^{1,2, \mathrm{~b}^{*}}$ and Ning Cai ${ }^{1, \mathrm{c}}$ \\ ${ }^{1}$ School of Public Administration, Zhejiang University, Hangzhou 310058, China \\ ${ }^{2}$ Lishui University, Lishui, 323000, China \\ ahjjzju@zju.edu.cn, ${ }^{\mathrm{b}}$ Iszqcn@163.com, ${ }^{\mathrm{c}}$ zjurgh@zju.edu.cn
}

Keywords: Living Garbage; NIMBY; Incineration; Processing Model

\begin{abstract}
After "Five Water Governance", the garbage processing shows exponential growth in Zhejiang, which causes a paradox with the behindhand garbage disposal facilities and processing model. Incineration is the main way of garbage disposal nowadays, but the incineration causes NIMBY. We analyze the technology, economy, market and social characteristics of garbage to discover the deep reason about NIMBY. Based on above, we build a new processing model includes pricing, operation and supervision mechanism. At last, we give suggestions from the perspective on publicity, organization guarantee and system construction.
\end{abstract}

\section{Introduction}

The green environmental demands of people continue to improve with the "five water governance" in Zhejiang Province. The amount of domestic garbage disposal volume increased exponentially, but the incineration capacity growth is very slow. The slow growth of waste incineration is behind the garbage incineration project on the ground, facing a serious "proximity effect dilemma." Neighboring effect means that has a negative external effect of the facilities were near the residents of the opposition and resistance to the effect (O 'Hare M, 1977) is a social phenomenon that has attracted much attention after China's economic development has entered a new stage (Yang Hibei, Zhu Hong, 2013). Based on this, this paper will be based on the technology, economic and economic aspects of the waste incineration project, market and social characteristics, analysis of waste incineration "proximity effect" arising from the underlying causes, and then mention a new model garbage incineration, covering various aspects of waste disposal pricing, operation and monitoring mechanism. Finally, this paper puts forward the corresponding policy recommendations through propaganda, organizational and institutional construction.

\section{The Status of Domestic Waste Incineration in Zhejiang Province}

"Garbage siege" Difficulties Highlighted, Incineration Capacity is obviously Insufficient. The increase of the capacity of municipal waste incineration cannot match the growth of municipal solid waste, resulting in the "garbage siege dilemma". According to statistics, during the province's average growth rate of domestic waste generated more than 5\%, especially since the construction of the river in "five water governance". The lack of professional waste disposal, a large number of garbage in accordance with the treatment. With "five water governance" as an opportunity for people to increasingly high requirements of green environment, such as in rural areas over the years, "nobody cares" junk with the environmental requirements increase was also vigorously clean up lead to surge in the total garbage.

The Incineration of Domestic Waste Incineration is Difficult to be Safe, Site Selection Difficult. The potential safety threats of waste incineration and the promotion of public awareness of environmental protection have exacerbated the "proximity effect". The Government tend to pay more attention to the price of corporate bidding is more economical in the waste incineration project tender. For the incineration technology and scale selection of the lack of scientific basis, the 
government not pay attention to the waste incineration plant, in terms of sensory on environmental protection, were given the public a bad impression.

The Regulatory System is Imperfect, Lack of Public Opinion Guidance. Waste incineration supervision involves a large number of departments, the division of labor is not clear, the responsibility is not clear, public opinion is relatively lack of guidance. Waste incineration plant supervision process is opaque, the whole link between the people and the community is relatively lack of participation, seriously affect the credibility of the government. Official media on the waste incineration of the positive publicity too little, lack of positive guidance to the public, is not conducive to the promotion and development of waste incineration project.

\section{The Garbage Incineration "proximity effect" Analysis}

Technical Characteristics. Waste incineration power generation process, will produce smoke, sulfur oxides, nitrogen oxides, hydrogen chloride, heavy metals, mercury, dioxins and other harmful substances. The tail gas will form a large number of toxic heavy metals fly ash, are required hazardous waste. The current waste incineration plant emissions and sewage and other emissions in line in Zhejiang Province, with national standards, but after the waste incineration of heavy metal fly ash treatment problems still need to be resolved.

Economical Characteristic. Waste incineration project has a typical negative external features, pollution will inevitably have an impact on the surrounding residents, resulting in "proximity effect." Waste incineration project belongs to the people's livelihood security infrastructure, the price subsidy mechanism and the lack of subsidy level, so that incineration enterprises to reduce the quality of burning to pursue economic interests exacerbate the residents of the waste incineration panic.

Market Characteristics. Waste incineration project has the characteristics of public goods, there are typical characteristics of necessities, both the need for private participation in the production and supply of public goods, but must be co-ordinated by the government in general, and through the corresponding government control to ensure and safeguard the public interest.

Social Characteristics. Waste incineration is a major social problem related to people's livelihood, related to urban construction and environmental protection, and people's lives are closely related to the government, enterprises and the focus of attention. With the public awareness of environmental protection will be increasingly attention, incineration standard requirements will be higher and higher.

\section{Policy Recommendations}

The Media Objective Reports for a Positive Guide the People, Cultivate a Rational Understanding. The media should adhere to professional ethics, the mainstream media should strengthen the positive publicity to create a positive positive public opinion, so that the people of the incineration of waste to form a rational understanding and value judgments. As part of the people opposed to the voice of waste incineration dominated by the participation of the mass media, "silent spiral" dilemma has been formed. Garbage management is a systematic project, it needs to adhere to the government-led, business owners, market allocation, social cohesion and media communication force "five-in-one".

The Government Increase Attention to Establish a Coordination Mechanism. The government should take the initiative to establish a garbage disposal coordination mechanism, attaches great importance to the problem of waste incineration, clear powers, the upper and lower active interaction to form a linkage coordination mechanism. Garbage problem is a relationship between people's livelihood safety, social stability and environment-friendly public welfare basic business, the disposal effect is directly related to social stability. The construction and operation of waste disposal projects and completion of pollution comprehensive management objectives need to be effectively linked with the leadership performance evaluation at all levels, into the assessment of 
scoring system, subordinate major leaders to regularly report to higher level of city garbage disposal situation and progress.

Scientific Forecast Planning Waste, Co-Ordination, to Promote the Construction of Intravenous Park. The government should make scientific predictions on the amount of waste, co-ordinate the cooperation of the county and the region, and actively learn from the experience of the province and promote the construction of the vein industrial park. "Garbage siege" dilemma tells us that garbage disposal must be ahead of planning, the relevant government departments should do a good job of garbage forecast, scientific, long-term planning waste disposal. Less the population, the amount of garbage is relatively small county-level city should break the administrative division of the restrictions to achieve county-level co-ordination and regional coordination of waste management. The economy is relatively developed, large amount of garbage in large cities that should achieve waste incineration power generation projects from the traditional miniaturization, decentralization to the park, centralized, large-scale development.

Improve the Project Approval System, Optimize the Publicity Process. Government departments should further improve the waste incineration project approval system for the construction of garbage disposal facilities to open green channel, optimize the publicity process, shorten the approval time limit, to promote the project implementation schedule. Waste incineration project is a major livelihood projects closely related to the people, from the project, environmental assessment, approval to the publicity should be transparent, but does not mean that the process should be complicated. At present, the process of construction of waste incineration project is not reasonable, the program is redundant and improper, and need to be optimized. In addition, the new project and the site transformation project should be distinguished, the approval system and the publicity process can not be one size fits all, or will hinder the garbage disposal facilities in the site of the standard transformation and expansion of expansion. At the same time, within the province should be introduced as soon as possible garbage disposal pricing norms and implementation methods, pay close attention to eliminate the old way, the formation of waste disposal fee collection and use of management practices, reasonable set of garbage disposal fees, the introduction of supporting policies.

Clear Responsibilities, Improve the Regulatory System and Methods. In view of the current chaos of the current regulatory system, the government should pay more attention to the development of domestic waste disposal facilities operating regulatory approach to clear the duties of different functional departments. The establishment of a sound garbage disposal enterprise pollution discharge daily monitoring system, the new living garbage incineration facilities must be installed automatic monitoring system and excessive alarm device, commissioned by a qualified unit of dioxin emissions every year from time to time detection.

\section{Acknowledgements}

This research was supported by Zhejiang Provincial Natural Science Foundation of China: Study on the generating mechanism of corporate strategic entrepreneurship: viewing from a perspective of network reconfiguration. NO. Y17G020006.

\section{References}

[1] Besfamille M, Lozachmeur J M, "NIMBY and mechanism design under different constitutional constraints". International Tax \& Public Finance, 2010, 17(2),114-132.

[2] Devine-Wright P, "Rethinking NIMBYism: The role of place attachment and place identity in explaining place-protective action”. Journal of Community \& Applied Social Psychology, 2009, 19(6),426-441.

[3] O'hare M, “ 'Not On My Block You Don't'-Facilities Siting and the Strategic Importance of Compensation". Massachusetts Institute of Technology Laboratory of Architecture and Planning, 1977. 
[4] Vittes M E, Iii P H P, Lilie S A, "Factors contributing to NIMBY attitudes". Waste Management, 1993, 13(2),125-129.

[5] Hunter S, Leyden K M. Beyond NIMBY: Explaining opposition to hazardous waste facilities[J]. Policy Studies Journal, 2010, 23(4):601-619.

[6] Wolsink M. Wind power and the NIMBY-myth: institutional capacity and the limited significance of public support[J]. Renewable Energy, 2014, 21(1):49-64.

[7] Hermansson H. The Ethics of NIMBY Conflicts[J]. Ethical Theory \& Moral Practice, 2007, 10(1):23-34.

[8] Zhang L, Chen J, Hao Q, et al. Measuring the NIMBY effect in urban China: the case of waste transfer stations in metropolis Shanghai[J]. Journal of Housing \& the Built Environment, 2017(3):1-18. 